\title{
Achieving consumer trust on Twitter via CSR communication
}

\begin{abstract}
Purpose: Corporations are under increasing pressure to communicate their position and policies with regards to corporate social responsibility (CSR), informing consumers about the corporations' good intentions and actions in order to appear trustworthy. Corporations have been asked to engage in a dialogue with their consumers. However, academic literature still lacks empirical research that examines how consumers react to asymmetric versus symmetric communication strategies.
\end{abstract}

Design/methodology/approach: The present paper closes this gap and evaluates how consumers react to different CSR communication approaches on social media, specifically on Twitter. The study is based on a sample of 507 respondents in the UK, representing a welleducated population of social media users. The sample was divided into two sub-samples, one receiving a set of tweets with an asymmetric CSR communication approach $(\mathrm{N}=242)$, the other one with a symmetric CSR communication approach $(\mathrm{N}=265)$.

Findings: Our main finding is that an asymmetric communication approach performs generally better than a symmetric communication approach. However, consumers' involvement and their own personal information processing mechanisms also play a significant role when evaluating the trustworthiness of corporations.

Originality/value: The paper provides insights in how corporations should communicate with consumers on Twitter and what characteristics they should take into consideration to achieve consumer trust.

Keywords: CSR communication, communication strategy, social media, stakeholder engagement, consumer trust

Article Classification: Research Paper 


\section{Introduction}

Corporate Social Responsibility (CSR) has emerged as one of the most important topics for organisations in the past decades. CSR has become an important driver of public opinion (Podnar and Golob, 2007). CSR communication efforts help companies to build a more positive reputation with stakeholders (Chernev and Blair, 2015), and to achieve superior financial performance (Porter and Kramer, 2006). In turn, effective CSR communication leads to higher levels of purchase intention among consumers, and generates positive evaluations among the stakeholders of an organization, which then improves the organization's image and reputation in the long term (Du et al., 2010). Research has shown that understanding the corporation's relationship with consumers is mainly dependent on consumer trust in corporate behaviour, which becomes especially important with regard to CSR efforts (Martínez and Rodríguez del Bosque, 2013). If promises made in CSR communication (e.g. the treatment of suppliers or employees) are not consistently kept within the credibility of the brand will suffer. In such scenarios, a lack of consistency in corporate behaviour can lead to a crisis. Therefore, CSR communication with consumers is more than just appealing advertising. In order to be regarded as trustworthy, a corporation needs to have a credible identity (Burmann and Zeplin, 2005). Hiscock (2001:1) even stated that "the ultimate goal of marketing is to generate an intense bond between the consumer and the brand, and the main ingredient of this bond is trust". From a corporate communication perspective, it is claimed that trust can be built if the corporate actions and communication are consistent with one another, if the corporation speaks with one voice, and if the corporation shows interest and responsibility towards external demands (Bentele and Seidenglanz, 2008; Schultz and Wehmeier, 2010).

With the development of social media, the ways in which corporations are communicating their CSR efforts in order to appear reliable and trustworthy are changing. Collaboration and mutual communication tools combined with ubiquitous access from all over the world are the key features of the Web 2.0 and its social media platforms such as Facebook, Twitter, or Instagram (Jansen et al., 2009). Scholars have commonly emphasized three main characteristics to describe the theoretical foundations of social media: the de-institutionalization of communication, the evolution of users as producers, and the interactivity in networks (Bechmann and Lomborg 2012). Social media can specifically empower users to create and filter content according to their own interests, so they can share them within their specific networks. From an organizational perspective, this results in a new understanding of stakeholders as being simul- 
taneously senders and receivers in social media organizational communication contexts. With regard to CSR, this new understanding of communicational practices becomes especially crucial. Reflecting the tools and possibilities provided by social media platforms, they seem to enable organisations to communicate directly and mutually with their stakeholders (Grunig, 2009).

Previous studies have researched CSR in social media, supporting the presence of an interest in CSR within social media, as well as exploring strategies for using social media to communicate CSR activities (Lee et al., 2013; Colleoni, 2013). The adoption of social media tools like Twitter is reinventing communications between corporations and society (Fieseler et al., 2010). Many brands have adopted Twitter as a marketing strategy, and furthermore are sharing information about their CSR on the social networking service (Lyon and Montgomery, 2013). The social media platform is one of the most important social media channels for achieving a new means of communicating with stakeholders (Stelzner, 2015). The platform enables stakeholders to engage with companies, regarding CSR or otherwise, more quickly and on a much larger scale than before, meaning that marketers face new challenges.

Companies are using Twitter in particular for CSR communication purposes; Etter (2014) found that a quarter of companies' Tweets refer to CSR efforts. As the literature on CSR and social media matures, this paper aims to add to such literature by exploring companies' CSR communications on the social networking site Twitter. Adopting such an approach allows us to advance CSR communication research in several ways. Firstly, it updates emerging research on social media by focusing on a better understanding of stakeholder perceptions of CSR communications on Twitter. Secondly, by building on the work of Morsing and Schultz (2006) and exploring how stakeholders perceive and react to specific CSR communications, the present study investigates the most effective CSR communication strategy for enhancing consumer trust. To summarize, the present study will examine the impact of communication strategies, and seeks to answer the following research question: How do asymmetric vs. symmetric CSR communication efforts affect consumer trust in the corporation?

\section{Theoretical background and development of hypotheses}

\section{Consumer trust}


Trust is regarded as the primary indicator of a strong management-stakeholder exchange relationship (Fang et al., 2008; Hansen et al., 2011). In that sense, Morgan and Hunt (1994:22) define $\underline{\mathbf{d}}$ trust as "central to successful relationship marketing". They further observed that trust enables the creation of long-term relationships between corporations and their consumers (Morgan and Hunt, 1994). Hence, consumer trust can be defined not only as belief that the provided product or service can be relied on but also that the long-term interests of the consumers will be served (Martínez and Rodríguez del Bosque, 2013). In line with these findings, MacLeod (2000) investigated the theory that much of the vocabulary of modern brandbuilding marketing strategies is associated with trust. Trust seems to be a great source of competitive advantage for corporations. Hence, a growing body of literature has emerged focused on investigating the impact of trust and its foundation in organizational contexts (Kramer, 1999). Understanding the relationship between corporations and their consumers that leads to brand commitment, loyalty etc. requires an analysis of the consumer's trust in the brand (Delgado-Ballester et. al, 2003).

It is widely acknowledged that conditions of trust arise when parties have something at risk, reflecting what Lewis and Weigert (1985: 969) called "rational prediction". In that sense, trust is mostly dependent on information processing to detect the likelihood of certain outcomes of future events. But this lacks an adequate definition of the phenomenon of trust. As Wicks et al. (1999: 100) argued, "although rational prediction is clearly an important part of trust, it provides a grossly incomplete understanding of trust on its own [...]. To warrant the label of trust, other conditions must be present." Their theoretical framework of trust includes two more, closely related characteristics that are essential to understand the phenomenon of trust: affect or emotion, and believe in moral character. Consequently, their understanding of trust went beyond rational prediction as the occurrence of trust dependent on an emotional bond created between two parties. As Wicks et al. described it (1999: 100), "the emotional bond in question is not just in the relationship but is, in large part, a belief in the moral character or "goodwill" of the trustee in the trusting relationship". Enriching these theoretical insights about trust with a communication perspective, it can be stated that in order to build trust, communication efforts have to incorporate rational as well as emotional components, or, in other words, to trigger informational and transformational processing of the communicated content (cf. Puto \& Wells 1984). Given that CSR communication refers to the moral character of the corporation, trust in the corporation can only be created when both ration- 
al/informational and emotional/transformational components become noticeable from a stakeholder perspective.

It is also important to point out that trust can be targeted towards an individual, a group, or an organization. In this paper, we draw on the theoretical framework described above to evaluate the degree to which an individual (the consumer) trusts an organization. When studying trust in organizational contexts, it is appropriate to examine the interaction of the individual to the organization (Currall and Inkpen, 2002). Accordingly, Pirson and Malhotra (2011) distinguished between interpersonal trust and organizational trust as it pertains to stakeholder perceptions. Interpersonal trust describes the phenomenon of an individual (origin) trusting another individual (referent), whereas organizational trust relates to an individual (origin) trusting an organization (referent). Thus, Pirson and Malhotra (2011: 1089) concluded, "stakeholder trust in organisations, then, entails the willingness of individuals (customers, employees, etc.) to accept vulnerability to the actions of an organization based on positive expectations".

When talking about the emergence of trust levels in corporate communication on social media platforms, such as Twitter, it is important to highlight that trust is socially embedded (Granovetter, 1985). Granovetter pointed out that models often used in the context of trust are based solely on a functionalistic transformation process, and neglect the essential element of relational dynamics. As Granovetter (1985: 490) stated "the role of concrete personal relations and structures (or networks) of such relations" is highly important for understanding the phenomenon of trust. Hence, building trustworthy relationships with corporate communication around an organization does not happen accidentally. The willingness of managers to create mutually trusting relationships with their stakeholders is a matter of strategic choice.

\section{CSR communication through digital platforms}

The emergence of social media has changed the landscape of organizational communication, allowing organisations to establish two-way, symmetric communication programs. Therefore, it would be expected that organisations would use social media to effectively communicate their CSR efforts and, by doing so, build consumers trust: social media can offer new chances for transparency and interactivity with stakeholders, which can in return trigger a positive evaluation of the organization's image and reputation, resulting in both short and long term consumer trust (Du et al., 2010). 
By utilizing social media, organisations can as a first step deliver information to their relevant stakeholder groups as they are actively looking for it (Colleoni, 2013). The proactive presentation of relevant information already meets some of the needs of stakeholders and shows a basic level of responsibility (Kent and Taylor, 1998). In that sense, communicating on social media about CSR issues can be regarded as a voluntary activity in terms of transparency and openness. Hence, by being available on social media platforms, organisations express their fundamental understanding of responsibility as dialogic process. Additionally, the organisations presence on social media can even foster CSR engagement solely by its dialogical implications. Communication is not about cosmetic improvements to the public image of an organisation, but "that CSR talk is in fact CSR action" (Golob et al., 2013: 179). Therefore, organisations that are already active in terms of CSR are more likely to create a greater communication network on Twitter and increase the number of followers within shorter time periods than organisations with lower CSR ratings (Lee et al., 2013).

Nevertheless, it is important to highlight that when communicating in the digital world, organisations have to take into account and follow the rules and dynamics of social media: openness, interaction and communication on an equal level. Otherwise, communicating CSR on social media can contain great risks, as its community easily reveals missing corporate information. Organisations should always be aware of the power their stakeholders hold, because they could spread contrasting information. Therefore, social media can expose firms to negative backlashes (Lyon and Montgomery, 2013). By not delivering transparent and substantial information, an organisation might face accusations of greenwashing being spread virally within the shortest of time periods. As a result, organisations are - by the very nature of social media - under more pressure to be socially responsible (Lee et al., 2013).

Increasing participation in corporate communication also results in decreasing organisational power to control public opinion (Castello et al., 2013; 2016). Furthermore, Pope and Waeraas (2016) argued that social media could lead to fragmentation of audiences, which could then make it harder to identify and engage with relevant interest groups. Conversely, Fiesler et al. (2010) argued, based on an empirical investigation of a CSR blog, that social media allows stakeholders to get access to information they could not reach before. As a result, organisations can establish a much more intense and interactive CSR communication network. Similarly, Saffer et al. (2013) tested whether the level of organisational Twitter interactivity af- 
fected the quality of organisation-public relationships. Their analysis indicated that interactivity on Twitter can influence the perceived quality of a relationship and demonstrate commitment (Saffer et al., 2013). Also, as shown by a study by Coyle et al. (2012), a high response rate leads to a better perception of an organization's trustworthiness and benevolence. Coyle et al.'s study particularly explored whether organisations can on the one hand demonstrate responsibility through engaging practices on social media, but have to ensure on the other hand that necessary resources are employed to responsibly engage stakeholders: "Simply acknowledging that a problem exists is not the level of engagement that consumers appear to expect" (Coyle et al., 2012: 38). In line with these findings, Cha et al. (2010) highlighted that engaging with stakeholders on social media platforms such as Twitter cannot be achieved impulsively or accidentally, but has to be strategically planned and then translated into continuous communication efforts.

Organisations tend to use social media in the same way they use other mass communication channels, and mainly distribute information with a one-way communication approach (Lovejoy et al., 2012). Reinforcing this difficulty in engagement practices, Etter (2013) found that interactivity levels of online CSR communication are generally low due to the fact that organisations behave passively on Twitter and only react when directly addressed. Furthermore, the analysis revealed a lack of CSR specialization in most corporate accounts. In addition, having implemented a specialized CSR account, organisations tend to have significantly higher levels of interactivity and could more adequately disseminate information in mutual conversations (Etter, 2013). Even so, as Colleoni (2013) showed in her analysis of the structural properties of the CSR community on Twitter, higher levels of corporate dialogic engagements do not necessarily lead to diverse networks with high densities. Instead, organisations tend to develop their own audiences fostering interest in specific organizational content rather than generic CSR interest (Colleoni, 2013). Thus, communication strategies need to be embraced covering the different contributions that social media can have to organizational communication processes.

It would be expected, therefore, that effective CSR communication would also require the effective use of social media. However, despite the importance of CSR communication on social media and the challenges organisations face, research focusing on practical implications of implementing CSR issues and engaging with stakeholders on social media, is still only just beginning to emerge. It still deficient in showing how organisations should use so- 
cial media as part of their public relations activities to create, reinforce or expand a trustworthy relationship with stakeholders through CSR communication. As Bonson and Flores (2011) stated, there is a clear shortage of strategies regarding successful corporate dialogue about CSR issues with relevant stakeholders. Organisations are aware of the new possibilities and values social media can provide, but are still sceptical about its actual ability to advance the organization (Waters et al., 2009).

\section{Asymmetric vs. symmetric CSR communication strategies on social media}

Based on Grunig and Hunt's (1984) characterization of models of public relations, Morsing and Schultz (2006) developed three CSR communication strategies: (1) the stakeholder information strategy, (2) the stakeholder response strategy, and (3) the stakeholder involvement strategy. Considering the specifics of CSR communication, the dialogue-oriented stakeholder involvement strategy has been identified in the literature as the outstanding method of CSR communication strategy. Thus, there is an increasing drive to implement such communication strategies in the daily activities of organisations (Johansen and Nielsen, 2011). The idea behind the involvement strategy is to evolve a mutually beneficial dialogue: ideally, "the company as well as its stakeholders will change as a result of engaging in a symmetric communication model, i.e. progressive iterations of sensemaking and sensegiving processes" (Morsing and Schultz, 2006: 328). As presented above, the dialogue strategy also fits well with the theory of organizational trust as socially embedded phenomenon (Granovetter, 1985). In contrast, asymmetric communication strategies are based on the information process described by Shannon and Weaver (1948) as a one-way process between transmitter and receiver.

It has been found that companies are reluctant to interact with stakeholders about CSR issues online (Moreno and Capriotti, 2009) and also that companies broadcast positive CSR content on social media, in a way that is reminiscent of traditional advertising strategies (Colleoni, 2013). Etter (2014) went a step further and described broadcasting as one-way communication, disseminating information to an anonymous public, whereas the reactive and the engagement strategies imply a two-way communication approach. However, the reactive strategy just responds to questions and remarks, while the engagement strategy promotes a proactive communication flow with questions and relates to other Twitter members. 
Following Morsing and Schultz's (2006) framework, broadcasting is described as one-way communication disseminating information to a mainly anonymous public; the reactive strategy is characterised by a two-way communication approach enabling interactions by answering questions and remarks; in contrast, the engagement strategy includes a proactive, two-way communication approach, which includes questions as well as approaches to other Twitter users (Etter 2014, p. 329). After having applied the specialised framework on actual tweets of organisations on Twitter, Etter (2014) revealed that most organisations follow an asymmetric broadcasting strategy and only a few communicate according to the engagement strategy. Hence, Etter (2014: 335) stated:

"The low level of symmetric communication and relationship building regarding CSR issues is an expression of the general trend that reflects corporate reluctance and anxiety about communicating and interacting with stakeholders online about CSR issues."

Taking these difficulties into account, Castello et al.(2016) conducted an in-depth longitudinal case study to investigate an organization's strategy when engaging and involving stakeholders on social media. The study showed that organisations have to recognise the polyphony of internal and external influences embodied in social media. To meet the resulting challenge of legitimacy building, organisations will have to adopt new cultural norms into their communication processes in order to remove the conditions of former structural power. Furthermore, organisations will have to introduce the terms of engagement which provide "an organizational frame of reference to give a sense of direction and coordination" (Castello et al., 2016: 424). The information strategy can be categorized as asymmetric communication, as the sender has power over the communication content. The response and involvement strategy can be categorized as symmetric communication. As asymmetric and symmetric strategies are divergent, the impact on consumers' trust will differ between the two strategies. We therefore hypothesize:

H1: Asymmetric vs. symmetric CSR communication strategies will have differing impacts on consumer' trust in the corporation.

\section{Consumers' processing of CSR communication}

Consumers as external stakeholders of corporations play a key role in evaluating CSR communication. By deciding to buy certain products, consumers can influence the achievements of a corporation on the market: they can either encourage or sanction corporate behaviour. Research has found empirical evidence for business benefits when corporations implement CSR (Aguinis and Glavas, 2012). Furthermore, an increasing interest among consumers in 
socially produced goods can be recognised (Brunner et al., 2012). However, consumers demand transparency from corporations, especially with regard to CSR. Such demands are especially present on social media as they allow consumers to communicate co-equally with corporations (Castello et al., 2016). Studies have shown that CSR that is perceived positively influences stakeholders' trust in the corporation (Martínez and Rodríguez del Bosque, 2013). CSR can even affect purchase intentions more strongly than the price of products (Mohr and Webb, 2005). Finally, achieving trust through CSR communication can impact the success of a corporation enormously as "CSR generates trust" (Pivato et al., 2008: 8). We thus define consumer trust in CSR as a belief that the corporation can be relied upon in terms of CSR and, further, that the corporation will behave in the long-term as communicated to the consumer (Martínez and Rodríguez del Bosque, 2013).

It is assumed that certain consumer characteristics influence how CSR communication is processed and evaluated (Du et al., 2010). For example, Mohr and Webb (2005) found that environmental CSR has a stronger effect on people's evaluation of a company, or this was based on a scale of social responsible consumer behaviour that compared people scoring high or low on this trait. Likewise, as proposed by Bhattacharya and Sen (2003), consumers are likely to identify with a company that offers them a positive and meaningful social identity. In other words, identification is enhanced when consumers perceive the corporation's character to be congruent with their own character. In that sense, corporations should give attention to those stakeholders whose expectations need to be handled carefully with regard to CSR. It is important to stress that CSR communication is seen as a way to actively involve interested parties, such as NGOs and 'green' consumers, in improving corporate CSR strategy (Trapp 2014). We define being 'green' as being aware of the possible negative social and environmental consequences of consumerism. Green consumers are those who consider the environmental impact of their purchase and consumption behaviours. Consequently, green consumers should evaluate mutual communication CSR efforts positively (Haws et al., 2010).

However, Bögel (2015) investigated whether highly involved stakeholders such as green consumers are particularly sceptical toward CSR. Such scepticism is further triggered when consumers face asymmetries of information in regard to CSR activities (Pomering and Johnson, 2009). To address these scepticism claims, Morsing and Schultz (2006) emphasized the importance of two-way, symmetric communications between firm and stakeholders that could 
foster a relationship where there is mutual understanding. In other words, green consumers can only be affected positively via CSR communication efforts when addressed via a mutual dialogue. Taking these theoretical assumptions into consideration we hypothesize that:

H2: Consumer trust is higher among consumers with high involvement (those being a "green" consumer) in symmetric communication.

To develop this further, not only the consumer's personal commitment toward CSR, but also the ways consumers process given information, is important for evaluating CSR communication efforts and building trust. Both rational and emotional elements play a significant role in the effectiveness of corporate communication regarding organizational trust. Based on information processing concepts, we assume that a message on social media platforms that is neither informational, exceptional or transformational, will not influence the consumer's perceptions of the corporation and will not contribute to consumers's trust (cf. Puto \& Wells, 1984).

On one hand, informational messages provide factual, relevant brand data, whilst transformational messages are associated with the brand experience. Informational messages could be perceived as messages displaying a high amount of substantial information. In this way, CSR is communicated through facts and figures as well as being characterised by meaningful information such as the value of the CSR investment, associations and outcomes (Farache, 2012). Therefore, we define informational communication as communication that targets the rationality of consumers by presenting reliable facts. Consumers feel that they are well informed and being treated honestly - an effect produced by the informational efforts of a communication campaign. On the other hand, transformational messages tend to be more emotional in nature. However, the fact that a message is emotional is not enough to characterise it as transformational. It also needs to display a degree of transformation - as the name suggests - related to the experience of using the brand. Therefore, the transformation occurs when the emotions are explicitly "related by consumers to the experience of owning or consuming the advertised brand" (Puto and Wells, 1984: 639). Such transformational learning relies on the individual's perceptions owing to the transformational nature of experiences relating to the communicated content. Transformational communication can thus be defined as communication that touches the consumer emotionally and let the consumer feel connected with the brand. It can be argued that the key to understanding a perceptional change toward a corporation is to focus on the transformational charac- 
$\underline{\text { teristics of its communication activities. Both informational needs and transformational }}$ learning are intertwined in forging and sustaining communication links. Hence, the emergence of organizational trust seems to be dependent on both informational as well as transformational communication efforts. We hypothesize that:

H3: Consumer trust is higher in consumers who regard tweets as (a) informational and (b) transformational.

Method and results

Study design

Our study was conducted via an online questionnaire, which contained an experimental setting, displaying either an asymmetric or symmetric CSR communication strategy. These two strategies were implemented in a set of tweets of fictitious company talking about its CSR initiatives to test the impact of these communication styles. To measure the individual characteristics we used well-established scales from the literature as explained below.

The questionnaire consisted of (1) a demographic module including a scale on "being green" (adapted from Haws et al., 2010), (2) a set of tweets within an (a) asymmetric or (b) symmetric communication strategy from a fictitious, beverage-selling corporation we created to avoid any predefined attitudes towards the communicating corporation. (2a) Participants in the asymmetric strategy were given three tweets that broadcasted CSR information from a fictitious company, so the company neither reacted to comments nor directly address other Twitter users. (2b) The fictitious corporation in the symmetric strategy engaged into the conversation by addressing others (through @-mentions and a direct approach, e.g. "What about you?") and responded consumer's reactions (three tweets in total). Finally, we included (3) a scale on information processing (adapted from Puto and Wells, 1984) of the given content and consumer's trust in the corporation (scale adapted from Morgan and Hunt, 1994; Sirdeshmukh et al., 2002).

We pre-tested the questionnaire with 10 experts in the marketing area as well as with 10 students, to ensure that the communication strategies differed sufficiently. The participants received three different tweets and could choose whether to react or not, whether 
to retweet or like the message, or whether to respond with a positive or negative comment. After they had react (or not) to these tweets, we asked the participants whether they would rate the tweets as informative or engaging in order to see whether the tweets reflected our intended manipulations. Our pre-test showed that the treatment had a significant effect on the theoretically relevant causal construct. Thus, we could be sure of the validity of our questionnaire, as our tweets accurately supported either an informative or an engaging CSR communication strategy.

The study was based on a sample of 507 students in the UK, representing a well-educated population with an affinity to social media, and was conducted in February 2016. The students were approached via an email list of student accounts including a link to the online questionnaire we had created. We sent the email to approximately 10,000 students. Our sample of 507 students then was divided into two sub-samples, one was given a set of tweets with an asymmetric CSR communication approach $(\mathrm{N}=242)$, and the other was given a set with a symmetric CSR communication approach $(\mathrm{N}=265)$. We thus enabled an experimental evaluation to test whether the CSR communication strategy (i.e. the treatment) caused a change in the level of trust in the corporation.

Results

To examine whether the CSR communication strategies impacted consumers trust differently, we performed an independent sample T-test that revealed a statistically relevant difference between the groups $(p<.05)$. Our results thus supported hypothesis 1 . Surprisingly, the asymmetric communication strategy had a significantly higher impact (Mean 4.16; SD .89) than the symmetric communication strategy (Mean 3.99; SD .91).

To test H2, H3(a), and H3(b) we applied a linear regression model and split the outcome of the file to compare the results of the two groups. We further included the control variables age, gender, twitter usage, perceived general credibility of corporate tweets (scale adapted from Obermiller and Spangenberg, 1998), and the person's need to evaluate (scale adapted from Jarvis and Petty, 1996). The results are displayed in table 1.

>>>>>>> Insert Table 1 around here $<<<<<<<<<$ 
As hypothesized, being a "green" consumer positively influenced consumers' trust after receiving the tweets. However, in line with our theoretical prediction, the influence was only significant within the symmetric communication approach. Hence, we can find support for our hypothesis 2 .

Furthermore, we found that informational as well as transformational processing of the tweets has a significant effect upon consumers' trust, which supported our hypotheses $3 \mathrm{a}$ and $3 \mathrm{~b}$. After analysing the coefficients, informational processing appeared to be more important than transformational processing in asymmetric communication situations whereas transformational processing seemed to have an higher impact in symmetric communication.

Additionally, we observed a positive influence of age within the symmetric communication strategy.

\section{Discussion}

The aim of this paper was to explore the impact of asymmetric vs. symmetric CSR communications on Twitter. The purpose was to gain insights into the ways in which companies' could better communicate CSR on Twitter, and how such approaches impact consumer trust in corporate behaviour. In line with the literature review on previous research about CSR communication and organizational trust, our analysis revealed a significant gap between asymmetric and symmetric communication approaches on Twitter. However, in contrast to theoretical assumptions promoting symmetric CSR communication (Morsing and Schultz, 2006), the asymmetric communication efforts of the fictitious corporation performed significantly better and to higher trust rates. Thus, our study contributes to recent research by questioning proposed success of mutual, symmetric communication strategies (Trapp 2014; Johansen and Nielsen 2011; Etter 2014; Morsing and Schultz 2006).

When talking about involvement strategies, it also has to be pointed out that consumers do not appreciate it when they feel that a company is engaging with them too excessively, especially when they detect self-promotion (Lyon and Montgomery, 2013). In the same context, Tetchner et al. (2017) found that a high rate of CSR communication in the Twitter platform can lead to negative stakeholder responses. This supports previous findings that a self-promoting approach to CSR communications can lead to negative reactions (Du et al., 2007). 
Therefore, at least on social media platforms such as Twitter, additional circumstances have to be considered when approaching consumer trust. In fact, research has shown that when stakeholders attempt to engage in a 'conversation' with corporations via stakeholder replies, many of them direct questions to the companies about their CSR initiatives (Tetchner et al., 2017). However, these questions were rarely answered by the companies, which could suggest that companies are trying to hide from criticisms regarding their activities. These insights corroborate with the literature findings that companies are reluctant to interact with stakeholders about CSR and that levels of direct communication with stakeholders are low (Etter, 2013; Angeles and Capriotti, 2009). Therefore, if consumers do not want to engage, or if, when they do, companies do not want to engage with them, the theoretical assumptions around the development of CSR as a two-way communication appear to be problematic. Perhaps the issue is not only present in CSR communication through digital media, but exacerbated by it. Corporations are more susceptible to scrutiny on social media as both power and control shifts from corporations to consumers. In this new situation, corporations are more vulnerable and prone to be questioned about their CSR performance. As argued by Perks et al. (2017) companies should apply the ethical premises when communicating CSR and then via an "open dialogue, accepting criticism, responding to questioning and action based on the outcome of the discourse organisations could fundamentally change the self-serving and instrumental public perception of corporations" (2017:12).

Especially in symmetric communication strategies, the involvement of the consumer seems to play a significant role when evaluating the trustworthiness of the corporation. First hints were given by the statistical support of our hypothesis 2 . The findings suggested that consumers who are already involved and who feel committed towards the topic are more likely to trust corporate behaviour within the symmetric communication strategy. Symmetric communication strategies are useful for gaining trust from highly involved consumers, particularly when they are young. Within the asymmetric strategy, such influence cannot be observed. A consumer who is not committed to a topic such as 'being green', might perceive direct approaches from the corporation on Twitter as too invasive. Although Twitter enables such approaches, consumers might it find irritating when directly addressed, as they are not 'friends' with the corporation, and want to keep their privacy. In that case, trust can be better obtained through asymmetric communication. The frequency of Twitter usage did not have any significant impact in either strategy. 
As presented in our theoretical framework, trust has to be seen as multidimensional phenomenon, including rational as well as emotional components. Both informational and transformational communication parts significantly impact the level of organizational trust. Within the asymmetric strategy, our findings reinforced the assumption that Twitter users are especially interested in messages that are rich in informational content and not so much in transformational content (Araujo et al., 2015). However, as our analysis revealed, within the symmetric strategy, transformational content - in other words the creation of an emotional bond - seems to have a greater impact on consumer trust. A qualitative study concentrating on message style and the creation of emotional bonds with regard to CSR could investigate this further and explain the linkage in a more comprehensive manner.

Managers could use these finding when addressing their stakeholders to further develop their CSR communication via twitter. Before this, managers have to know their audiences very well. Following such an analysis, the content and frequency of CSR messages to create trusting relationships with stakeholders would be a matter of strategic choice. In the worst case, where managers do not know with whom they are communicating, the asymmetric strategy performs significantly better in terms of consumer trust and, therefore, should be used. Age and gender do not play a significant role in that strategy with regard to consumer trust. However, when targeting highly involved, green consumers with CSR communication approaches, the symmetric communication strategy can also be useful, especially when the audience is younger. The decision in favour of the symmetric communication strategies also implies the use of emotions etc. to trigger transformational processing of the given information. In contrast, the asymmetric informational content seems to be more relevant to gain consumer trust. Thus, our findings support previous research on information processing concepts (Bögel, 2015), as it discusses empirically, how an asymmetric approach could be beneficial to corporations, despite the fact this is not usually favoured by CSR communication scholars.

\section{Limitations and further research}

The present study carried out an experiment using a fictitious brand and investigating students. We tried to replicate the Twitter platform characteristics accurately by making use of hashtags and mimicking its layout. However, we are aware that this was an unnatural setting, and that this may have implications for the results. Another factor that was not taken into account was the use of direct messages that companies might employ when dealing with their 
stakeholders. It was not possible to incorporate this element into our research design. Also, whilst the use of a fictitious brand guarantees that no previous experience or association will be taken into account, it does not reflect day-to-day life where consumers interact with familiar brands.

As our sample contains only University students, it would be interesting to conduct a similar study using consumers with diverse educational backgrounds and of different ages. Running a case study example using a real company and its consumers could further develop the current research and overcome some of its limitations.

Previous research examined CSR communication from a theoretical perspective and looked at companies' strategies. This paper makes a contribution to the research on CSR communication via social media, as it explores the consumer's response to asymmetric and symmetric communication strategies. Contrary to the literature, we found out that asymmetric communication strategies perform better than symmetric, except when directed towards green consumers, who have a more positive response towards symmetric strategies. 


\section{References}

Aguinis, H. and Glavas, A. (2012), "What we know and don't know about corporate social responsibility a review and research agenda", Journal of Management, Vol. 38 No.4, pp. 932- 968.

Angeles, M. and Capriotti, M. (2009), "Communicating CSR, citizenship and sustainability on the web", Journal of Communication Management, Vol. 13 No. 2, pp. 157-175.

Araujo, T., Neijens, P. and Vliegenthart, R. (2015), "What motivates consumers to re-tweet brand content? The impact of information, emotion, and traceability on pass-along behaviour"', Journal of Advertising Research, Vol. 55 No. 3, pp.284-295.

Bentele, G. and Seidenglanz, R. (2008), "Trust and credibility: prerequisites for communication management”, in Zerfass, A., van Ruler, B. and Sriramesh, K. (Eds), Public Relations Research: European and International Perspectives and Innovations, pp. 49-62.

Bögel, P.M. (2015), "Processing of CSR communication: insights from the ELM", Corporate Communications: An International Journal, Vol. 20 No. 2, pp.128-143.

Bonson, E. and Flores, F. (2011), "Social media and corporate dialogue: the response of glob al financial institutions", Online Information Review, Vol. 35 No.1, pp. 34-49.

Bhattacharya, C., and Sen, S. (2003), "Consumer-Company Identification: A Framework for Understanding Consumers' Relationships with Companies", Journal of Marketing, Vol. 67 No.2, pp.76-88.

Burmann, C. and Zeplin, S. (2005), "Building brand commitment: A behavioural approach to internal brand management", Journal of Brand Management, Vol. 12 No. 4, pp.279-

300.

Brunner, C.B., Esch, F.R. and Kinscher, N., (2012), "Communicating corporate social respon sibility: Empty promises or smart strategy?" in Advances in Advertising Research (Vol. III) pp. 105-117, Gabler Verlag.

Castello, I., Morsing, M., and Schultz, F. (2013), "Communicative dynamics and the polyphony of corporate social responsibility in the network society", Journal of Business Ethics, Vol. 118 No. 3, pp.683-694.

Castello, I., Etter, M. and Årup Nielsen, F. (2016), "Strategies of legitimacy through social media: the networked strategy", Journal of Management Studies, Vol. 53 No. 3,

pp.402-432.

Cha, M. , Haddadi H., Benevenuto F., and Gummadi K. (2010), "Measuring user influence in Twitter: the million follower fallacy". International AAAI Conference on Weblogs and Social Media, pp.10-17.

Chernev, A. and Blair, S. (2015), "Doing Well by Doing Good: The Benevolent Halo of Corporate Social Responsibility", Journal of Consumer Research, Vol. 41 No.6,

pp.1412-1425.

Colleoni, E. (2013), "CSR communication strategies for organizational legitimacy in social media" Corporate Communications: An International Journal, Vol. 18 No. 2, pp.228-

248.

Coyle, J.R., Smith, T. and Platt, G. (2012), "I'm here to help. How companies' microblog responses to consumer problems influence brand perceptions", Journal of Research in Interactive Marketing, Vol. 6 No. 1, pp.27-41.

Currall, S. C. and Inkpen, A. C. (2002), "A multilevel approach to trust in joint ventures", Journal of International Business Studies, Vol. 33 No. 3, pp. 479-495.

Delgado-Ballester, E., Munuera-Alemán, J.L. and Yagüe-Guillen, M.J. (2003), "Development and validation of a brand trust scale", International Journal of Market Research, Vol. 45 No. 1, pp.35-54.

Du, S., Bhattacharya, C.B. and Sen, S. (2007), "Reaping relational rewards from corporate social responsibility: The role of competitive positioning", International Journal of Re- 
search in Marketing Vol. 24 No. 3, pp. 224-241.

Du, S., Bhattacharya, C.B. And Sen, S. (2010), "Maximizing business returns to corporate social responsibility (CSR): The role of CSR communication", International Journal of Management Reviews, Vol. 12 No.1, pp.8-19.

Etter, M. (2013), "Reasons for low levels of interactivity (Non-) interactive CSR communication in Twitter", Public Relations Review, Vol. 39 No.5, pp.606-608.

Etter, M. (2014), "Broadcasting, reacting, engaging - three strategies for CSR communication in Twitter", Journal of Communication Management, Vol. 18 No. 4, pp.322-342.

Fang, E., Palmatier, R. W., Scheer, L. K., and Li, N. (2008), "Trust at different organizational levels", Journal of Marketing, Vol. 72 No. 2, pp. 80-98.

Farache, F. (2012) "Scepticism in CSR advertisement" Hermes Journal of Language and Communication in Business, Vol. 49 No. 1, pp.9-18.

Fieseler, C., Fleck, M. and Meckel, M. (2009), "Corporate Social Responsibility in the Blogosphere", Journal of Business Ethics, Vol. 91 No. 4, pp.599-614.

Golob, U., Podnar, K., Elving, W.J., Ellerup Nielsen, A. and Thomsen, C., (2013), "CSR communication: quo vadis?", Corporate Communications: An International Journal, Vol. 18 No. 2, pp.176-192.

Granovetter, M. (1985), "Economic action and social structure: The problem of embeddedness", American Journal of Sociology, Vol. 91 No. 3, pp. 481-510.

Grunig, J. E., (2009), "Paradigms of global public relations in an age of digitalisation", PRism Vol. 6 No. 2, pp 1-19.

Grunig, J.E. and Hunt, T. (1984), Managing Public Relations. New York: Holt, Rinehartand Winston.

Haws, K L., Winterich, K.P., and Naylor, R.W. (2010), "Seeing the world through greentinted glasses: motivated reasoning and consumer response to environmentally friendly products", Journal of Macromarketing,Vol. 5 No. 2 , pp. 18-39.

Hiscock, J. (2001), "Most trusted brands", Marketing, 1 March, pp. 32-33

Jansen, B., Zhang, M., Sobel, K., and Chowdury, A. (2009), "Twitter power: Tweets as electronic word of mouth", Journal of the American Society for Information and Technology, Vol. 60 No. 11, pp. 2169-2188.

Johansen, T.S. and Nielsen, A.E. (2011), "Strategic stakeholder dialogues: a discursive perspective on relationship building", Corporate Communications: An International Journal, Vol. 16 No. 3, pp.204-217.

Kaplan, A.M. and Haenlein, M. (2010), "Users of the world, unite! The challenges and opportunities of social media", Business Horizons, Vol. 53 No.1, pp. 59-68.

Kent, M.L. and Taylor, M. (1998), "Building dialogic relationships through the world wide web", Public Relations Review, Vol. 24 No.3, pp.321-334.

Lee, K., Oh, W.-Y. and Kim, N. (2013), "Social media for socially responsible firms: analysis of Fortune 500's Twitter profiles and their CSR/CSIR Ratings", Journal of Business Ethics, Vol. 118 No. 4, pp.791-806.

Lee, H-H. M., Van Dolen, W. and Kolk, A. (2013) "On the role of social media in the 're sponsible' food business: blogger buzz on health and obesity issues", Journal of Business Ethics, Vol. 118 No.4, pp.695-707.

Lewis, J., and Weigert, A. (1985), "Trust as a social reality", Social Forces, Vol. 63 No. 4, pp. 967-985.

Lomborg, S. and Bechmann, A. (2012), "Tracking social media data paths", in Catac 2012.

Lovejoy, K., Waters, R.D. and Saxton, G.D. (2012), "Engaging stakeholders through Twitter: How nonprofit organisations are getting more out of 140 characters or less" Public Relations Review, Vol. 38 No. 2, pp.313-318.

Lyon, T.P., Montgomery, A.W. (2013), "Tweetjacked: the impact of social media on corporate greenwash", Journal of Business Ethics, Vol. 118 No. 4, pp.747-757. 
MacLeod, C. (2000), "Does your brand need a makeover?", Marketing, 21 September, pp. 24-27.

Martínez, P. and Rodríguez del Bosque, I. (2013), "CSR and customer loyalty: The roles of trust, customer identification with the company and satisfaction", International Journal of Hospitality Management, Vol. 35(Dec), pp.89-99.

Mohr, L. and Webb, D. (2005), "The Effects of Corporate Social Responsibility and Price on Consumer Responses", Journal of Consumer Affairs, Vol. 39 No. 1, pp.121-147.

Moreno, A. and Capriotti, P. (2009), "Communicating CSR, citizenship and sustainability on the web" Journal of Communication Management, Vol. 13 No. 2, pp.157-175.

Morgan, R. M., and Hunt, S. D. (1994), "The commitment-trust theory of relationship marketing", Journal of Marketing, Vol. 58 No. 1, pp. 20-38.

Morsing, M. and Schultz, M. (2006), "Corporate social responsibility communication: stakeholder information, response and involvement strategies", Business Ethics: A European Review, Vol. 15 No. 4, pp.323-338.

Perks, K., Recalde, M., Farache, F. and Kollat, J. (2017), "A critical reflection on the role of dialogue in communicating ethical CSR through digital platforms" in Lindgreen, A., Vanhamme, J., Maon, F., and Watkins, R., (Eds), Digital Social Responsibility, Routledge, forthcoming.

Pirson, M. and Malhotra, D. (2011), "Foundations of Organizational Trust: What Matters to Different Stakeholders?" Organization Science, Vol. 22 No. 4, pp.1087-1104.

Pivato, S., Misani, N. and Tencati, A. (2008), "The impact of corporate social responsibility on consumer trust: the case of organic food", Business Ethics: A European Review Vol. 17 NO. 1, pp. 3-12.

Podnar, K. and Golob, U. (2007), "CSR expectations: the focus of corporate marketing", Corporate Communications: An International Journal, Vol. 12 No. 4, pp.326-340.

Pomering, A. and Johnson, L.W. (2009), "Advertising corporate social responsibility initiatives to communicate corporate image: Inhibiting scepticism to enhance persuasion", Corporate Communications: An International Journal, Vol. 14 No. 4, pp.420-439.

Pope, S. and Waeraas, A. (2016), "CSR-Washing is rare: a conceptual framework, litera ture review, and critique", Journal of Business Ethics, Vol. 137 No. 1, pp. 683-694.

Porter, M.E. and Kramer, M.R. (2006), "Strategy \& Society. The Link Between Competetive Advantage and Corporate Social Responsibility" Harvard Business Review, (December), pp.1-13.

Puto, C.P. and Wells, W.D. (1984), "Informational and Transformational Advertising: the Differential Effects of Time", Advances in Consumer Research, Vol. 11 No.1,pp. 638643.

Ruehl, C.H. and Ingenhoff, D. (2015), "Communication management on social networking sites. Stakeholder motives and usage types of corporate Facebook, Twitter and YouTube pages", Journal of Communication Management, Vol. 19 No. 3, pp.288-302.

Saffer, A.J., Sommerfeldt, E.J. and Taylor, M. (2013), "The effects of organizational Twitter interactivity on organization-public relationships" Public Relations Review, Vol. 39 No. 3, pp.213-215.

Sirdeshmukh, D., Singh, J., and Sabol, B. (2002), "Consumer trust, value, and loyalty in relational exchanges", Journal of Marketing, Vol. 66, pp. 15-37.

Schultz, F. and Wehmeier, S., (2010). "Institutionalization of corporate social responsibility within corporate communications: Combining institutional, sensemaking and communication perspectives" Corporate Communications: An International Journal, Vol. 15 No. 1, pp.9-29.

Shannon, C. E. and Weaver, W, (1948), The mathematical theory of communication. University of Illinois Press, Urbana. 
Stelzner, M.A. (2015) "Social Media Marketing Industry Report: How marketers are using social media to grow their business", Social Media Examiner, available at: http://www.socialmediaexaminer.com/social-media-marketing-industry-report-2015/ (accessed 11 November, 2016).

Taylor, M., Kent, M.L. and White, W.J. (2001), "How activist organisations are using the Internet to build relationships" Public Relations Review, Vol. 27 No. 3, pp.263-284.

Tetchner, I., Farache, F. and Kollat, J. (2017) "CSR communications on Twitter: an exploration into stakeholder reactions", in Grigore, G., Stancu, A., and McQueen, D. (eds) Corporate Responsibility and Digital Technology: International perspectives through online communities, Palgrave, forthcoming.

Trapp, N.L. (2014), "Stakeholder involvement in CSR strategy-making? Clues from sixteen Danish companies" Public Relations Review, Vol. 40 No. 1, pp.42-49.

Waters, R.D., Burnett E., Lamm A., and Lucas J. (2009), "Engaging stakeholders through social networking: How non-profit organisations are using Facebook", Public Relations Review, Vol. 35 No. 2, pp.102-106.

Wicks, A.C., Berman, S.L. and Jones, T.M. (1999), "The Structure of Optimal Trust: Moral and Strategic Implications", The Academy of Management, Vol. 24 No. 1, pp.99-116. 
Table 1

Dependent variable: Consumers trust

\begin{tabular}{lcc}
\hline \hline & \multicolumn{2}{c}{ Std. coefficients (SD) } \\
\cline { 2 - 3 } & $\begin{array}{c}\text { Asymmetrical } \\
\text { comm. strategy }\end{array}$ & $\begin{array}{c}\text { Symmetrical } \\
\text { comm. strategy }\end{array}$ \\
\hline Age & $-.056(.025)$ & $-.134^{* *}(.023)$ \\
Gender & $.037(.096)$ & $.039(.093)$ \\
Frequency of Twitter usage & $.046(.023)$ & $.046(.022)$ \\
Credibility of corp. tweets & $.240^{* * *}(.047)$ & $.280^{* * *}(.046)$ \\
Need to evaluate & $.069(.061)$ & $.080(.056)$ \\
Being green & $-.015(.039)$ & $.098^{*}(.039)$ \\
Informational processing & $.247 * * *(.090)$ & $.194^{* * *}(.078)$ \\
Transformational processing & $.239 * * *(.062)$ & $.283^{* * *}(.062)$ \\
\hline R Square & .319 & .405 \\
\hline \hline
\end{tabular}

Significant levels: ${ }^{*} \mathrm{p}<.05 ;{ }^{* *} \mathrm{p}<.01 ;{ }^{* * *} \mathrm{p}<.001$ 